\title{
Collocated Interaction: New Challenges in 'Same Time, Same Place' Research
}

Joel E. Fischer

University of Nottingham, UK

joel.fischer@nottingham.ac.uk

Martin Porcheron

University of Nottingham, UK

porcheron@acm.org

Andrés Lucero

University of Southern Denmark University of Glasgow, UK

lucero@acm.org

Aaron Quigley

University of St Andrews, UK

aquigley@acm.org
Stacey D. Scott

Engineering University of Waterloo

stacey.scott@uwaterloo.ca

Luigina Ciolfi

Sheffield Hallam University, UK

I.ciolfi@shu.ac.uk

John Rooksby

john.rooksby@glasgow.ac.uk

Nemanja Memarovic

University of Zurich, $\mathrm{CH}$

memarovic@ifi.uzh.ch

Paste the appropriate copyright/license statement here. ACM now supports three different publication options:

- ACM copyright: ACM holds the copyright on the work. This is the historical approach.

- License: The author(s) retain copyright, but ACM receives an

- exclusive publication license.

- Open Access: The author(s) wish to pay for the work to be open

Open Access: The author(s) wish to pay for the wor
access. The additional fee must be paid to ACM.

This text field is large enough to hold the appropriate release statement assuming it is single-spaced in Verdana 7 point font. Please do not change the size of this text box.

Each submission will be assigned a unique DOI string to be included here

\begin{abstract}
In the 25 years since Ellis, Gibbs and Rein proposed the time-space taxonomy, research in the 'same time, same place' quadrant has diversified, perhaps even fragmented. The goal of this one-day workshop is to bring together researchers with diverse, yet convergent interests in tabletop, surface, mobile and wearable technologies, and those interested in the social aspects of interaction, such as conversation analysis and ethnomethodology. These communities have matured considerably, and produced significant exemplars of systems, methods, and studies concerned with collocated interactions. Yet, new challenges abound as people wear and carry more devices than ever, creating fragmented device ecologies at work, and changing the ways we socialise with each other. In this workshop we seek to start a dialogue to look back as well as forward, review best practices, discuss and design paperprototypes using the collocated design framework, to consider how we might address new and future challenges through collocated design practice.
\end{abstract}

\section{Author Keywords}

co-located interaction; face-to-face; design; CSCW.

\section{ACM Classification Keywords}

H.5.3. Group and Organization Interfaces: Computersupported cooperative work. 


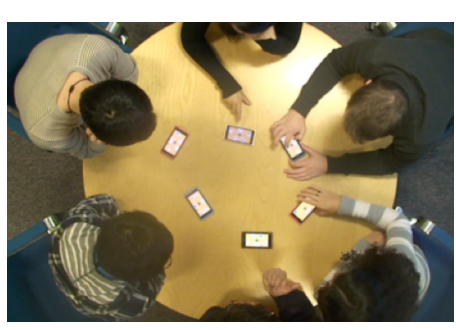

Figure 1: FlexiGroups explores multi-device binding for collaborative interaction.

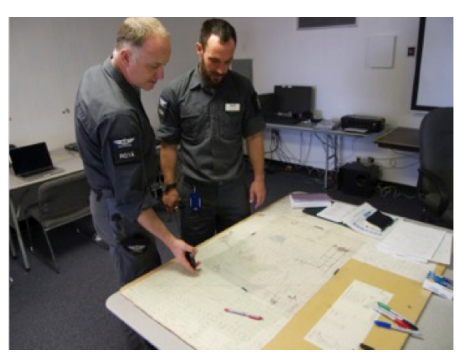

Figure 2: Analysis of orderly ways in which situational uncertainty is managed in disaster response.

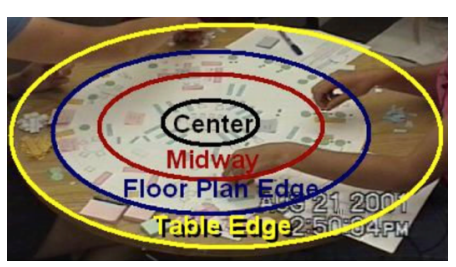

Figure 3: Work has identified territoriality in collaborative tabletop workspaces.

\section{Introduction}

Since its early years of meeting room technologies [8], CSCW work in the 'same time, same place' quadrant of Ellis et al.'s time-space taxonomy [4] has diversified. For example, researchers have turned their attention from workplace settings to the home [20] and public spaces [19], and developed communities within testament of a diverse and active community, including at CSCW [22], ITS [1], MobileHCI [15], MAB [18], CHI [14], NordiCHI [12], and ECSCW [3,5].

Research concerned with collocated interaction has adopted diverse foci that chart a compelling sociotechnical design space, with contributions ranging from technical solutions to in-depth studies of social interactions around technology. Technical contributions range from cross-device interaction techniques (Figure 1) [13] to fully integrated systems in complex, safety critical work settings [9], to the design and study of multi-device ecologies [25]. This work complements a long-standing tradition of systems design ethnography from early work studying London Underground control rooms [9], air traffic control [2], to disaster response (Figure 2) [7].

Furthermore, a range of naturalistic studies with ubiquitous computing technologies such as public displays [18], interactive tabletop (Figure 3) [21] and mobile phones [19], have been conducted with a goal to understand how they impact face-to-face interactions. This work often pays particular attention to the interactional resources people employ in face-toface interaction, such as gaze, gestures, and bodily coorientation, and its 'implications for design', such as how mutual observability of action may be a key resource for tabletop collaboration [10], how collocated groups manage notifications by drawing on embodied resources [6], or how people coordinate and engage around public displays in social interactions [18]. One of the aims of this workshop is to bring together expertise and experience in these diverse domains to address new and future challenges in designing for collocated interaction settings.

\section{New Challenges}

This workshop invites contributions across a range of topical interests to examine and collect exemplars of current and future challenges the CSCW community faces in collocated interaction research. Here, we only have space to briefly sketch two domains to exemplify the diversity of the research, although potential participants are encouraged to contribute challenges from their own collocated settings.

Collocated interaction in casual social settings In particular, the pervasiveness of mobile devices in everyday life raises challenging problems of societa scale. Public commentator Sherry Turkle tells us to 'stop googling, let's talk' [24], and elsewhere, she tells us about how phones socially isolate us from each other [23]. One of her interviewees captures the sentiment "Our texts are fine. It's what texting does to our conversations when we are together that's the problem".

While Turkle's and other public commentators sentiment is captivating, it is but a sign of public concern that should motivate further research of faceto-face interaction involving technology. However, rather than sweeping generalisations and fingerpointing, our empirical research has the ability to paint a perhaps complicated, yet valid picture of how 


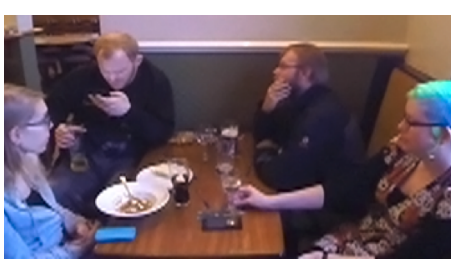

Figure 4: Identified practices of interleaving mobile device use with talk in collocated groups.

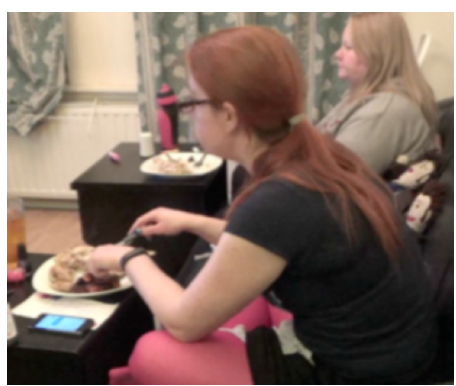

Figure 5: Work has captured the orderly use of how screens are used together in living rooms.

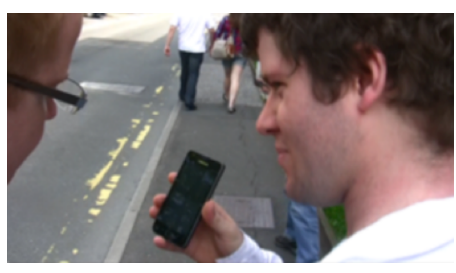

Figure 6: Study of mobile device notification co-management in collocated groups. technology-enhanced social encounters really play out, in a multitude of settings including at work, at home, play, and travel. For example, in-depth ethnographic research has revealed the subtle and skilled ways in which we embed phone use in conversations in pubs (Figure 4) [19], living rooms (Figure 5) [20], and collaborative photo-taking (Figure 6) [6]. As Rooksby et al. [20] point out, "technology does not feature in the living room as something that brings or breaks intimacy, but rather mobile devices are things that enter an intimate environment and are used with respect to intimacy" (p.257).

\section{Collocated interaction in multi-device ecologies}

Multi-device ecologies have become common as people carry and wear more and more devices, and as our environments in which we travel, work, and play is becoming increasingly equipped with displays, projectors, and networked services, to name but a few. For collaborative teamwork settings, these ecologies can fragment team and task awareness [22], research points to the importance that personal displays are complemented with shared displays that provide a common reference point [25].

Ethnographic studies of collaborative work settings have also shown that members routinely work with assemblies of physical and digital resources, engaging in coordination and translation work to transfer information across the 'seams' of the resources (e.g. [7]). In their study of disaster response planning work, Fischer et al. found the (analogue) 'bird table' to be a sort of 'common frame of reference' for members to read progress and to align their own contributions (Figure 2) [7]. A challenge for CSCW designers wishing to support collocated work is then not just to focus on the digital realm, but to what is done manually, by hand, and with physical objects.

In summary, the overarching goal of the workshop is to reflect on the insights of collocated interaction design research across these diverse domains. For instance, how can we leverage findings from studies of specific technologies (e.g. mobile phones, tabletops, or public displays) to understand the impact of overall

technology ecology on face-to-face interactions? How can we build on these findings to design technology that stimulates and supports face-to-face interactions instead of hampering them?

\section{Themes}

For this workshop, we invite contributions (either posters or position papers) relating to the design and study of collocated interaction, including but not limited to any of the following:

- Studies of settings involving collocated interaction - Designs, deployments and studies of social/groupware and CSCW systems for collocated settings;

- Discussions of methods and tools to study and evaluate socio-technical systems with a focus on collocated settings;

- Examples and 'thick descriptions' of interaction and conversation analysis and ethnographic reports;

- Approaches and examples of how studies of faceto-face interaction inform design;

- Techniques of sensing 'social context', e.g. collocation, conversation, and bodily orientation; 
- Concepts and design examples of systems that support collocated group-awareness and coordination;

- Explorations of interaction techniques aimed at supporting collocated interaction

- Conceptual frames aiding the understanding of collocated interaction.

- Case studies and lessons learned from evaluating the impact of technology on co-located interactions.

- Studies or examples of mixed-presence CSCW systems.

\section{Pre-Workshop Plans}

We will set up a dedicated website for announcements, communication, related work and accepted contributions. The call for participation will be distributed in relevant academic mailing lists related to CSCW and through social media. In addition, we will actively solicit submissions (via personal contacts and targeted invitations) from a broad range of researchers whose work relates to the workshop topic or who can make a significant contribution to the workshop. Attendance will be limited to 20 participants.

Potential workshop participants should submit a 3-6 page position paper (including references), or a poster and a 2-page abstract, describing their interest and/or previous work related to the workshop topic. All selected papers will be available online on the website prior to the workshop for consenting authors, and participants will be asked to read all accepted submissions ahead of the workshop to help ground the discussion.

\section{On the Day}

The one-day workshop is structured into a series of different segments, each designed to encourage provocative and engaging interactivity through the exploration of a number of topics related to challenges within the field of collocated interactions. The first half of the workshop, the morning, will be devoted to getting to know each other and reflecting on existing and on-going work in collocated interactions. In order to ground later activities and acquaint attendees with each other, each participant will be asked to briefly present their position paper or poster to the group this will be fast-paced and time-limited in relation to the number of submissions. The remainder of the morning will involve mapping the design space and key challenges through discussion of the submissions and related work (e.g. by affinity diagramming) to prepare the development of design ideas in the afternoon.

The remainder of the morning and most of the afternoon will be devoted to a hands-on ideation and prototyping session in small groups to develop design ideas related to the topics introduced by attendees. This will include the introduction of the collocated interaction design framework [16] to help facilitate ideation, while allowing participants to form novel concepts based on the existing challenges within the field identified in the previous session.

We will make use of the remainder of the afternoon to stimulate an active discussion and reflection based on the outcomes of the workshop activities. The purpose of this will be to answer key questions of the workshop, including how the CSCW community can adapt new approaches whilst building upon existing ideas to face current and future challenges within collocated 
interactions. This outcomes of the day, including this discussion, will be recorded (with consent from participants) to allow for follow up activities. Concrete tangible outcomes of the interactive sessions of workshop will include a map of the design space, and paper prototypes. We seek to encourage follow up activities such as joint publications and workshops.

\section{Organisers}

The organisers have recently co-organised a range of workshops that explored facets of collocated interaction $[1,5,12,14,15,17,22]$. In this workshop we seek to build on recent workshops by bringing together expertise in tabletop, mobile, and wearable technologies with social interaction research, to address new and emerging challenges in diverse CSCW domains from casual face-to-face settings to collaborative work environments.

Joel Fischer is an Assistant Professor at the School of Computer Science and a member of the Mixed Reality Lab at the University of Nottingham. His research focuses on understanding and supporting human activities and sense-making in collaborative real-world domains. He has co-organised workshops on collocated interaction at $\mathrm{CHI}$, MobileHCI, NordiCHI and ECSCW.

His research has been published at leading conferences in HCI (e.g. CHI, UbiComp, CSCW), and and has received Best Paper Awards at $\mathrm{CHI}$ ' 13 and AAMAS '15.

Martin Porcheron is a PhD student in the Mixed Reality Lab at the University of Nottingham. His work has focused on the use of mobile devices within collocated groups. His research includes examining the social implications of mobile device use and the positioning of mobile devices as resources that people can draw upon in conversations.

Andrés Lucero is an Associate Professor of interaction design at the University of Southern Denmark in Kolding. His recent work at Nokia focused on the design and evaluation of novel interaction techniques for mobile collocated interactions. He has recently coorganised successful workshops at ITS '13, CHI '15, and MobileHCI '15.

Aaron Quigley is a Professor in Human Computer Interaction in the School of Computer Science at the University of St. Andrews, where he is also Director for the HCI research group, SACHI. Aaron's research interests include surface and multi-display computing, human computer interaction, pervasive and ubiquitous computing and information visualization and has served on over 80 program committees and has been involved in chairing roles of over 20 international conferences and workshops.

Stacey Scott is an Associate Professor of Systems Design Engineering at the University of Waterloo in Canada. Her research focuses on human-computer interaction and computer-supported collaboration, with a special interest in developing technologies that enhance human-human interaction in face-to-face environments. She has been researching co-located collaboration technologies, including interactive tabletops and walls, and multi-surface systems, for over 15 years. She has co-organized five previous CSCW workshops (2000, 2002, 2004, 2006, 2015).

Luigina Ciolfi is a Reader in Communication at C3RI The Cultural, Communication and Computing Research 
Institute at Sheffield Hallam University. Her research focuses on technologies to support human interaction within the physical space, based on an understanding of the relationship between people, activities and their locales. She has organised a several international workshops (at venues such as ACM CHI, ACM CSCW and $\mathrm{ECSCW}$ ) on topics from museum technologies and ubiquitous computing to mobile work. She is the author of over 80 peer reviewed publications in the human-centred computing domain, and has served in numerous service roles for international conferences.

John Rooksby is a Research Associate in Computer Science at the The University of Glasgow. His research focuses on everyday life, and how technology features within this. His recent work on co-located interaction includes video studies of photocopying and people watching television (published at CSCW and ECSCW respectively).

Nemanja Memarovic is a postdoc at People and Computing lab at the University of Zurich. His research focuses on how human interactions in public spaces may be enhanced through networked public displays. He has co-organised workshops on collocated interaction at NordiCHI '14 and at UbiComp '12 and '13, and he is a regular PC member for PerDis.

\section{Acknowledgements}

Joel E. Fischer is supported by EPSRC grants EP/L02392X/1 and EP/M000877/1. Martin Porcheron is supported by EPSRC grants EP/G037574/1 and EP/G065802/1. Nemanja Memarovic is supported by Forschungskredit of the University of Zurich, grant no. FK-15-020.

\section{References}

1. Craig Anslow, Laurent Grisoni, Pedro Campos, and Andrés Lucero. Collaboration Meets Interactive Surfaces (CMIS): Walls, Tables, Mobiles, and Wearables. To appear in Proceedings of the Tength ACM International Conference on Interactive Tabletops and Surfaces (ITS '15).

2. Richard Bentley, John A. Hughes, Dave William Randall, Tom Rodden, Pete Sawyer, Daniel Goodman Shapiro, and Ian Sommerville. 1992. Ethnographically-informed systems design for air traffic control. In Proceedings of the 1992 ACM conference on Computer-supported cooperative work (CSCW '92). ACM, 123-129.

http://dx.doi.org/10.1145/143457.143470

3. Luigina Ciolfi, Gabriela Avram, Erik Grönvall Chiara Rossitto, and Louise Barkhuus. 2013. CSCW at the Boundary of Work and Life. In ECSCW 2013 Adjunct Proceedings. Aarhus University Press, 8489

4. Clarence A. Ellis, Simon J. Gibbs, and Gail Rein. 1991. Groupware: some issues and experiences. Communications of the ACM 34, 1 (January 1991), 39-58. http://dx.doi.org/10.1145/99977.99987

5. Joel E. Fischer, Stuart Reeves, Steve Benford, and Chris Greenhalgh. 2013. First International

Workshop on Designing Mobile Face-to-Face Group Interactions. In ECSCW 2013 Adjunct Proceedings. Aarhus University Press, 104-111.

6. Joel E. Fischer, Stuart Reeves, Stuart Moran, Chris Greenhalgh, Steve Benford, and Stefan RennickEgglestone. 2013. Understanding Mobile Notification Management in Collocated Groups. In Proceedings of the 13th European Conference on Computer Supported Cooperative Work (ECSCW '13). Springer, 21-44.

http://dx.doi.org/10.1007/978-1-4471-5346-7_2

7. Joel E. Fischer, Stuart Reeves, Tom Rodden, Steve Reece, Sarvapali D. Ramchurn, and David Jones. 
2015. Building a Birds Eye View: Collaborative Work in Disaster Response. In Proceedings of the $33 r d$ Annual ACM Conference on Human Factors in Computing Systems (CHI '15). ACM, 4103-4112. http://dx.doi.org/10.1145/2702123.2702313

8. Jonathan Grudin. 1994. Computer-supported cooperative work: History and focus. Computer 5: 19-26. http://dx.doi.org/10.1109/2.291294

9. Christian Heath and Paul Luff. 1992. Collaboration and control: Crisis management and multimedia technology in London Underground Line Control Rooms. Computer Supported Cooperative Work (CSCW) 1, 1: 69-94.

http://dx.doi.org/10.1007/BF00752451

10. Eva Hornecker, Paul Marshall, Nick Sheep Dalton, and Yvonne Rogers. 2008. Collaboration and interference: awareness with mice or touch input. In Proceedings of the 2008 ACM conference on Computer supported cooperative work (CSCW '08). ACM, 167-176.

http://dx.doi.org/10.1145/1460563.1460589

11. Christophe Hurter, Rémi Lesbordes, Catherine Letondal, Jean-Luc Vinot, and Stéphane Conversy. 2012. Strip'TIC: exploring augmented paper strips for air traffic controllers. In Proceedings of the International Working Conference on Advanced Visual Interfaces (AVI '12), Genny Tortora, Stefano Levialdi, and Maurizio Tucci (Eds.). ACM, 225-232. http://dx.doi.org/10.1145/2254556.2254598

12. Pradthana Jarusriboonchai, Sus Lundgren, Thomas Olsson, Joel Fischer, Nemanja Memarovic, Stuart Reeves, Paweł Woźniak, and Olof Torgersson. 2014. Personal or social?: designing mobile interactions for co-located interaction. In Proceedings of the 8th Nordic Conference on Human-Computer Interaction: Fun, Fast

Foundational (NordiCHI '14). ACM, 829-832. http://dx.doi.org/10.1145/2639189.2654840
13. Tero Jokela and Andrés Lucero. 2014. FlexiGroups: binding mobile devices for collaborative interactions in medium-sized groups with device touch. In Proceedings of the 16th international conference on Human-computer interaction with mobile devices \& services (MobileHCI '14). ACM, 369-378.

http://dx.doi.org/10.1145/2628363.2628376

14. Andrés Lucero, James Clawson, Kent Lyons, Joel E. Fischer, Daniel Ashbrook, and Simon Robinson. 2015. Mobile Collocated Interactions: From Smartphones to Wearables. In Proceedings of the 33rd Annual ACM Conference Extended Abstracts on Human Factors in Computing Systems (CHI EA '15). ACM, 2437-2440.

http://dx.doi.org/10.1145/2702613.2702649

15. Andrés Lucero, Danielle Wilde, Simon Robinson, Joel E. Fischer, James Clawson, and Oscar Tomico. 2015. Mobile Collocated Interactions With

Wearables. In Proceedings of the 17th International Conference on Human-Computer Interaction with Mobile Devices and Services Adjunct (MobileHCI '15). ACM, 1138-1141.

http://dx.doi.org/10.1145/2786567.2795401

16. Sus Lundgren, Joel E. Fischer, Stuart Reeves, and Olof Torgersson. 2015. Designing Mobile Experiences for Collocated Interaction. In Proceedings of the 18th ACM Conference on Computer Supported Cooperative Work \& Social Computing (CSCW '15). ACM, 496-507.

http://dx.doi.org/10.1145/2675133.2675171

17. Nemanja Memarovic, Vassilis Kostakos, Geraldine Fitzpatrick, and Albrecht Schmidt. 2013. SOFTec 2013: second workshop on computer mediated social offline interactions. In Proceedings of the 2013 ACM conference on Pervasive and ubiquitous computing adjunct publication (UbiComp '13 Adjunct). ACM, 1373-1380.

http://dx.doi.org/10.1145/2494091.2497358

18. Nemanja Memarovic, Marc Langheinrich, Florian Alt, Ivan Elhart, Simo Hosio, and Elisa Rubegni. 
2012. Using public displays to stimulate passive engagement, active engagement, and discovery in public spaces. In Proceedings of the 4th Media Architecture Biennale Conference: Participation (MAB '12). ACM, 55-64.

http://dx.doi.org/10.1145/2421076.2421086

19. Martin Porcheron, Joel E. Fischer, and Sarah Sharples. 2016. Using Mobile Phones in Pub Talk. To appear in Proceedings of the 19th ACM Conference on Computer Supported Cooperative Work \& Social Computing (CSCW '16).

http://dx.doi.org/10.1145/2818048.2820014

20. John Rooksby, Timothy E. Smith, Alistair Morrison, Mattias Rost, and Matthew Chalmers. 2015.

Configuring Attention in the Multiscreen Living Room. In Proceedings of the 14th European

Conference on Computer Supported Cooperative Work (ECSCW '15). Springer, 243-261.

http://dx.doi.org/10.1007/978-3-319-20499-4_13

21. Stacey D. Scott, M. Sheelagh T. Carpendale, and Kori M. Inkpen. 2004. Territoriality in collaborative tabletop workspaces. In Proceedings of the 2004 ACM conference on Computer supported cooperative work (CSCW '04). ACM, 294-303. http://dx.doi.org/10.1145/1031607.1031655

22. Stacey D. Scott, T. C. Nicholas Graham, James R. Wallace, Mark Hancock, and Miguel Nacenta. 2015. "Local Remote" Collaboration: Applying Remote Group AwarenessTechniques to Co-located Settings. In Proceedings of the 18th ACM Conference Companion on Computer Supported Cooperative Work \& Social Computing (CSCW'15 Companion). ACM, 319-324.

http://dx.doi.org/10.1145/2685553.2685564

23. Sherry Turkle. 2011. Alone Together. Basic Books.

24. Sherry Turkle. 2015. Stop Googling. Let's Talk. Retrieved September 27, 2015 from http://www.nytimes.com/2015/09/27/opinion/sund ay/stop-googling-lets-talk.html
25. James R. Wallace, Stacey D. Scott, Eugene Lai, and Deon Jajalla. 2011. Investigating the Role of a Large, Shared Display in Multi-Display

Environments. Computer Supported Cooperative Work (CSCW) 20, 6: 529-561.

http://dx.doi.org/10.1007/s10606-011-9149-8 